\title{
Strengthening Biostatistical Skills of Medical Doctors and Health Professional through A Hands-on Approach
}

\author{
Gita Sekar Prihanti * \\ Faculty of Medicine, University of Muhammadiyah Malang, Indonesia \\ Jalan Bendungan Sutami Nomor 188A, Kota Malang, Jawa Timur 65145 \\ *Corresponding author: gitasekarprihanti@gmail.com
}

\begin{abstract}
Background: In the area of evidence based medicine (EBM), biostatistics and epidemiology are considered as the main elements aiding the health professional to design a research study, understand the literature, and make decisions about patient care. Planners and policy-makers in the medical health science education institute need to apply research-based information to maintain and improve quality of teaching-learning processes. Methods: Eighteen until twenty-five medical doctors and health professionals from FM UMM, other universities and hospital, participated in this intervention, which consisted of four day workshop. We assessed the impact of this intervention through pre and post-workshop evaluations. Results: Significant result were obtained that showed the benefits of a biostatistics workshop in clinical research that can help medical doctors and health professionals to develop a conceptual understanding of statistical ideas and their applications to investigate problems of medical and health research $(p=0,0000)$. The results indicate that workshop approach can facilitate developing statistical knowledge and skills to solve medical and health research problems. Incorporating biostatistics into evidence based medicine practice and curriculum would pave new ways into research fields. MHS faculty should include more effective biostatistics training in their faculty development programs and curricula to successfully prepare educators and students for this important lifelong learning skill.

Keywords: biostatistics; evidence based medicine, medical doctors, health professional, research.
\end{abstract}

\section{INTRODUCTION}

Biostatistics is the study of the development and application of statistical methods in analyze and solve public health and biomedical research, clinical, and social problem. Understanding biostatistics and the basic skill of it become one of the primary/core competencies for practitioners, researchers, and students in health care. Biostatistics key concepts use examples from daily problems faced by public health and medicine department. The problem is that the existing service and statistical training agencies use only very common sample questions, whereas, the field of health and medicine has the specific and strict requirements that different from other fields such as engineering, social and others. In particular, the statistical training materials offered will be different in the application of statistics for medical field, engineering, economics, education and other areas.

For example, many research in the field of health and medicine use sample test of animals to humans for clinical trials in the context of evidence-based medicine (EBM) that require data analysis and statistical tests that very specific because of the risk to the lives of living beings while research in agriculture or engineering, for example, do not risk the lives of living beings. Clinically relevant research can be in a form of a basic medical sciences research, but mostly in form of patients-oriented clinical research. Accuracy and 
precision test of a diagnostic method (including physical examination), reliability test of a prognosis marker, effectiveness and safety test of a therapy method, rehabilitation care and prevention methods is one example of the specificity of research in health and medicine. A clinical discovery can change the currently accepted diagnostic methods or therapy trials into a new method that is more robust, precise, effective and safe. Ultimately, this will greatly help the patients.

Biostatistical specificity makes statisticians unable to help fulfill the purposes and objectives of research students in the fields of health and medicine. Moreover, student of health and medicine also often have difficulty in sharing the same perception or consulting the general statistical expert. This will lead research results to be less optimal and any other limitation. Therefore, we need ways of problem-oriented teaching method, so that it is in accordance with the required competencies.

Such issues will be taken from the real problems on the field, or issues that were published in scientific journals in the field of public health. The biostatistics teaching process is one of the activities organized by the Center for Health and Medical Biostatistics Service and Training. It is expected that the Center for Health and Medical Biostatistics Service and Training through MEARS (Medical and Health Research Statistic), can help: (1) the community has competence in the field of biostatistics so as to solve the problems of quantitative scientific research in the field of public health; (2) Communities have competence in applying biostatistics for the benefit of public health management and services, and (3) Communities have the competence to utilize quantitative evidence (statistics) to draw scientific conclusions, decision making and the preparation of public health policies (evidence based public health care).

Medical doctors who pursue or explore the biostatistics knowledge field is lacking. Similarly, a lot of statistical is non-physician personnel. Therefore we need collaboration between them in a team so that they can work together and ultimately improve the quality of care.

Market opportunities of the Center for Health and Medical Biostatistics Service and Training is very large, it can be seen from: (1) The high number of students in health (nursing, pharmacy, midwifery, nutrition) and medicine (general practitioners, specialists, dental, veterinary) in public and private universities in Malang; (2) The number of professionals in the fields of health and medicine that are also high and in line with the growing number of health facilities including hospitals. Target goals of the event include students and professionals as well as health and medical practitioners. Its market opportunity is people who require data analysis can take advantage of the services provided by the Center. (3) The students' interest to get to know operational technic of biostatistics becomes a must as they doing the Final Assignment, both at the level of Theses or Dissertation.(4) There is an increasing tendency of interest and research assignments as a prerequisite for graduation. (5) The existence of research methodology and biostatistics as compulsory subjects at every level of higher education. (6) Presumption and tendency from students and the public that Biostatistics as a science that is difficult to understand and it becomes "scourge". (7) The demands of evidence based medicine of medical therapies. The study found that patients who received evidence based treatment obtained better results than the one who does not. This means that today's society is more critical and fonder of an evidence-based health care because it is safer, more effective, and more efficient. (8) With the demands of EBM it will lead to a market share of hospitals, and pharmaceutical companies as well as the need for Scientific Journals and publications.

"Tridharma" in colleges required teacher as an educator, researcher and perform community service. In addition to lecturer as a researcher, in the learning process at FM 
UMM lecturer also acts as a mentor for students in making a final project that is used to qualify the medical degree $(S-1 \mathrm{Ked})$. Various kinds of research titles and a variety of research methods proposed by students require the knowledge and techniques of making a good research proposal in accordance with the standard rules of research.

Research conducted by the students in addition to be used to meet the bachelor degree requirements, each year students are also required to follow a research competition both university-level and national levels and is expected that every year FM UMM student is able to present and achieve something while attending the National Science Week activities (PIN). Thus, the lecturers should improve the quality and quantity of their research to obtain external research grant and was able to guide student research and get awarded in the following PIN. Currently, the similar training was only held in faculty with an irregular schedule, so the chance of time owned by participants sometimes not in accordance with the schedule offered by faculty.

From the background above, Center for Health and Medical Biostatistics Service and Training called MEARS needs to be done, to provide satisfying biostatistics services and get optimal research results in health and medicine to contribute to the development of new knowledge and clinical evidence of either therapy, diagnostic, prognostic and etiology as part of evidence-based medicine (EBM). In addition, MEARS as Center for Health and Medical Biostatistics Service and Training also needs to be done to support health and medicine student competency in the field of information management to:

1. Take advantage of information and communications technology and health information in the health and medical practices.

2. Access and assess information and knowledge.

3. Make use of information and communications technology and health information to improve the quality of health services.

4. Utilize management skills of health information to make lifelong learning.

5. Disseminate information and knowledge effectively to other health professions, patients, the public, and other interested parties to improve the quality of health care.

6. Utilize management skills to disseminate information in the field of health information.

The Research Methodology Block is a block or a module which takes place on 4th semester research phase in preparation for students' final assignment that must be made at the 5th semester. Subjects of research methodology and biostatistics are taught in this block. This block requires students to be active in the preparation of the final project and student creativity program (PKM).

Resources at the Faculty of Medicine, University of Muhammadiyah Malang which includes lecturer, students, and laboratories will gain fame in creating role models in biostatistics practices and can improve academic atmosphere, especially in the field of research and community service as part of the implementation of the "Tridharma" in Colleges. Support from Directorate of Research Development and Community Service, Directorate General of Higher Education, in National Education Department through Science and Technology Program for INNOVATION AND CREATIVITY CAMPUS (Ib$\mathrm{KIK}$ ), is desirable for the development of innovations or breakthroughs in terms of Center for Health and Medical Biostatistics Service and Training industry / business owned by faculty.

In the area of evidence based medicine (EBM), biostatistics and epidemiology are considered as the main elements aiding the health professional to design a research study, understand the literature, and make decisions about patient care. Although research in medicine are increasing in number, many educators in medical and health sciences (MHS) faculty do not completely understand the process of statistical investigations and planning statistical inquiry in medical and health related decisions. Thus justifies the ongoing 
integration of biostatistical training into medical institution educational settings. Furthermore, planners and policy-makers in the MHS education institutions need to apply research-based information to maintain and improve quality of teaching-learning processes. Designing and conducting such research requires statistical knowledge and skills. In this regard, not only faculty members in the departments of medical sciences, but also other medical doctors and health-related professionals who completed their studies years ago, are expected to be familiar with statistical thinking and to understand the process of statistical investigations. (Bazargan, 2006) The need for medical researchers to employ a wide variety of statistical designs in clinical, genetic, basic science and translational settings justifies the ongoing integration of biostatistical training into medical center educational settings and informs its content (Brimacombe,2014)

Toward meeting the above objectives, a series of biostatistics workshop in clinical research was designed at Faculty of Medicine University of Muhammadiyah Malang (FM UMM) in Indonesia. The workshop was developed and implemented to provide medical doctors and health professional with opportunities to get their hands on statistical investigations.

\section{MATERIALS \& METHOD}

Biomedical statistic is a very distinctive area, and different from the statistics in general. An expert in biomedical statistics is not only required considerable statistical understanding but also the understanding of medical and health fields as well as skilled in analyzing and interpreting the data that is valid as the basis for evidence based medicine (EBM). To strengthen the lecturer of medicine and health competence at FM UMM faculty, the medical school faculty and medical faculty of FM UMM lecturers were trained at FM UMM on 18-22 July 2016 at the "Workshop Biostatics for Clinical Research" and was followed by the participants of the medical school faculty from other universities. The event was organized by MEARS and Faculty of Medicine, University of Malang. This first training or workshop consists of four sub-themes which are:

1. The Sample Size and the Selection of Statistical Tests.

2. Therapeutic Research.

3. Diagnostic Research.

4. Etiology Research

Eighteen until Twenty-five medical doctors and health professionals from FM UMM, other universities and hospital, participated in this intervention, which consisted of four day workshop. We assessed the impact of this intervention through pre and postworkshop evaluations.

This workshop consisted of interactive lectures and practice of statistics with SPSS software using case studies. Training theme was based on simple to complex considerations.

\section{RESULT AND DISCUSSION}

Training evaluation has shown encouraging results. The evaluation was done quantitatively. Here are the results of the evaluation of pre-test and post-test training per day. 
Table 1 Evaluation of training day 1 "the sample size and the selection of statistical tests"

\begin{tabular}{cccccc}
\hline & $\mathrm{n}$ & Min & Max & Mean & SD \\
\hline MSD Pretest & 20 & 0.00 & 53.30 & 25.34 & 15.83 \\
MSD Posttest & 20 & 20.00 & 100.00 & 79.67 & 20.79 \\
\hline
\end{tabular}

Table 2 Evaluation of training day 2 "therapeutic research"

\begin{tabular}{rccccc}
\hline & $\mathrm{n}$ & Min & Max & Mean & SD \\
\hline Therapeutic Pretest & 25 & 0.00 & 53.30 & 33.33 & 14.91 \\
Therapeutic Posttest & 25 & 66.70 & 100.00 & 92.52 & 8,454 \\
\hline
\end{tabular}

Table 3 Evaluation of training day 3 "diagnostic research"

\begin{tabular}{cccccc}
\hline & $\mathrm{n}$ & Min & Max & Mean & SD \\
\hline Diagnostics Pretest & 23 & 0.00 & 50.00 & 20.00 & 11.18 \\
Diagnostics Posttest & 23 & 50.00 & 100.00 & 83.91 & 15.44 \\
\hline
\end{tabular}

Table 4 Evaluation of training day 4 "etiognostic research"

\begin{tabular}{cccccc}
\hline & $\mathrm{n}$ & Min & Max & Mean & SD \\
\hline Etiognostic Pretest & 18 & 0.00 & 40.00 & 21.11 & 11.82 \\
Etiognostic Posttest & 18 & 70.00 & 100.00 & 86.11 & 8.49 \\
\hline
\end{tabular}

Table 5 Evaluation of the overall 4 days training

\begin{tabular}{cccccc}
\hline & $\mathrm{n}$ & Min & Max & Mean & SD \\
\hline 4 Days Training Pretest & 13 & 10.43 & 42.50 & 23.62 & 10.47 \\
4 Days Training Posttest & 13 & 75.00 & 93.75 & 87.59 & 5.98 \\
\hline
\end{tabular}

The number of participants who attended the training for 4 consecutive days was 13 people who then viewed the results of its pre-post value. From pre-test result, min-max values of 10.43-42.5 with an average of 23.62 and a standard deviation of 10.47 were obtained. After join the training, very satisfactory results were obtained. The smallest minimum value was 75 and the maximum became 93.75. On the average, post test results of 13 participants were 87.59 with a standard deviation of 5.98 .

Furthermore, the value of pre-posttest will be tested using the Wilcoxon test since normality rule was not met. Results obtained are as follows: 
Table 6 Wilcoxon Test Result

\begin{tabular}{ccccc}
\hline & Rank & N & Mean Rank & Sig \\
\hline \multirow{2}{*}{$\begin{array}{c}\text { Posttest-Pretest Average for 4 } \\
\text { days }\end{array}$} & Negative & 0 & 0 & \\
& Positive & 13 & 7 & 0,001 \\
& Constant & 0 & & \\
\hline
\end{tabular}

The results of the Wilcoxon test in the table above show that all respondents experienced a positive increase (posttest> pretest) so that the difference of pretest and posttest is very significant.

Through attending the workshop, the participants are expected to understand the importance of statistical data not only for research purposes, but also in decision making for the purpose of improving health services quality. Furthermore, the participant also expected to be able to fully understand the results of research, and to make decisions after critically reviewing the evidence after equipped with knowledge and skill of biostatistics from this training (Daher \& Farzana, 2010). Moreover, with increasing biostatistical skill through this workshop, it could be enabled academic clinicians to contribute significantly to the body of medical and health research literature (Enders, 2011). Working in conjunction with a statistician can also be a key training opportunity for the academic clinicians beginning a clinical research (Huet et al., 2009).

Teaching of biostatistics as a separate entity is unlikely to change the scenario. So more integrated approaches that demonstrate how biostatistics can affect patient care decisions, as suggested in other studies, may be more effective, which will revive the importance of biostatistics in clinical decision making, which requires both knowledge of biological processes and interpretation of research reports (Batra et al,, 2011).

Research evaluation of biostatistics suggested that EBM may represent an ideal vehicle for improved teaching of biostatistics. Possible solutions to the limitations in teaching biostatistics can be incorporation of contextual learning with heavy emphasis on application into biostatistics course which can be quite helpful (Batra et al., 2011). Statistical courses must be reformulated and one of the most challenges is to create courses with emphasis on interpretation and applications, without loss in the learning of the theory (Paes, 2015). Biostatistics and research methodology should be taught as a continum, with its relevance to thinking about health and disease (Sami, 2010). Furthermore, doctor's statistical training needs may have changed due to advances in information technology and the increasing importance of evidence-based medicine (Miles et al., 2010).

Biostatistics is perceived as an important element of EBM, and successfull efforts to teach biostatistics may benefit from incorporating statistical concepts into EBM teaching framework already in place (Wadhwa et al., 2015). Educators have responded by increasing training in critical appraisal and biostatistics throughout the continuum of medical education (Windish et al., 2007).

\section{CONCLUSION}

Significant result were obtained that showed the benefits of a biostatistics workshop in clinical research that can help medical doctors and health professionals to develop a conceptual understanding of statistical ideas and their applications to investigate problems of medical and health research. The results indicate that workshop approach can facilitate developing statistical knowledge and skills to solve medical and health research 
problems. Incorporating biostatistics into EBM practice and curriculum would pave new ways into research fields. MHS faculty should include more effective biostatistics training in their faculty development programs and curricula to successfully prepare educators and students for this important lifelong learning skill.

\section{REFERENCES}

Bazargan, A. (2006). Strengthening research and statistical skills of medical doctors through a hands-on approach: A case study from Iran.

Batra, M., Mudir, G., Subbha, S.D., \& Preshant, R. (2014). Perception of Dental Professionals towards Biostatistics, Hindawi Publishing Corporation International Scholarly Research Notice. doi:10.1155/2014/291807.

Brimacombe, M.B. (2014). Biostatistical and medical statistics graduate education. BMC Medical Education, 14, 18.

Daher, A.M., \& Farzana, A. (2010). The perceptions of a biostatistics and epidemiology module: views of year 2 medical students from a Malaysian university: A crosssectional survey. BMC Medical Education, 10, 34.

Enders, F. (2011). Evaluating mastery of biostatistics for medical researchers: need for a new assessment tool. Clin Transl Sci, 4(6), 448-454.

Huet, B., Adams, M.S., \& Chul, A. (2009). Bridging clinical investigators and statisticians: writing the statistical methodology for a research proposal. J Investig Med, 57(8), 818-824.

Miles, S., Gill, M.P., Louise, S., Le, S., \& Sam, J. L. (2010). Statistics teaching in medical school: opinions of practising doctors. BMC Medical Education, 10, 75.

Paes, A. T. (2015). Perspectives on teaching biostatistics for undergraduate medical students using team-based learning, In: M.A. Sorto (Ed.), Advances in statistics education: developments, experiences and assessments. Proceedings of the Satellite conference of the International Association for Statistical Education (IASE), July 2015, Rio de Janeiro, Brazil. @2015 ISI/IASE iaseweb.org/Conference_Proceedings.php

Sami, W. (2010). Biostatistical and medical statistics graduate education. Biomedica, 26, 80-84.

Wadhwa, M., Pulkit, K., \& Thanveer, K. (2015). Knowledge and attitude of medical and dental postgraduate students toward practice of biostatistics. Journal of Postgraduate Medicine, Education and Research, 49(1), 1-4.

Windish, D.M., Stephen, J.H., \& Michael, L.G. (2007). Medicine residents' understanding of the biostatistics and results in the medical literature. JAMA, 298(9), 1010-1022. 